\title{
Analysis of large-scale transmission line icing and galloping event in the Jilin province during November 2020
}

\author{
Xunjian $\mathrm{Xu}^{1,2, *}$, and $L i \mathrm{Li}^{2}$ \\ ${ }^{1}$ College of electrical and information engineering, Hunan University, 410012, Changsha, China \\ ${ }^{2}$ State Grid Hunan Electric Power Corporation Limited, 410129, Changsha, China
}

\begin{abstract}
A large-scale transmission line icing and galloping event occurred in Jilin province during November 2020. First of all, the circulation background and the evolution characteristics of key meteorological factors of the icing and galloping event are analysed, which provide basis for the prediction and early warning of the galloping event in the future. It is found that, the warm and wet air transported northward to the central part of Northeast China due to the abnormal northward position of the western pacific subtropical high, combined with the strong cold air activity in the north, the cold and warm air converged in the middle of Northeast China, resulting in the co-occurrence of temperature decline, precipitation, gale and high humidity, which is the direct cause of this large-scale galloping event. Then, the prediction and actual situation of the disaster event are analysed. The results show that the power gird icing and galloping numerical prediction system accurately predicted the influence area and disaster intensity three days in advance, which can provide effective support for future disaster response. Finally, some relevant suggestions are put forward according to the characteristics of this disaster.
\end{abstract}

\section{Introduction}

Transmission line galloping is the low frequency and large amplitude self-excited vibration of transmission line under the action of strong wind and light ice. The frequency of line galloping is about $0.1-3 \mathrm{~Hz}$, the maximum amplitude can reach $10-12 \mathrm{~m}$, and the motion path is mainly up and down or elliptical track [1]. Galloping has serious harm to the line, mainly in three aspects. First, the transmission line electrical fault. The up and down movement of the transmission line leads to too close distance between different conductors, resulting in flashover and trip, and in serious cases, conductor may ablation and disconnection. Second, the mechanical failure of lines and towers. The huge tension change caused by the galloping of transmission line leads to the loosening and falling of bolts, the damage of fittings and insulators, the broken strand and wire of conductor, the damage of tower materials and even the collapse of tower. Third, the harm to the power grid. Galloping often occurs in large areas at the same time, it is easy to cause frequent tripping

*Corresponding author: bearxxj@126.com 
or even damage of multiple lines, resulting in large-area power outage. At the same time, due to galloping, the structure of line tower is damaged, which takes a long time to restore power supply, threatens the stability of power supply, and easily leads to major power grid security accidents [2-3].

There are records of transmission line galloping disasters in areas from Heilongjiang Province to Hunan Province. According to statistics, there are $312220 \mathrm{kV}$ and above voltage grade transmission lines tripped due to galloping in State Grid Company of China during 2010-2020, among which Bohai rim, Henan and Hubei Province are the three most prone areas to dance disasters in China [4-6]. However, a serious ice disaster occurred in Jilin Province during November 18-22, 2020, which caused large-scale transmission line icing and galloping.

In this work, the background of meteorological circulation system and the evolution characteristics of key meteorological elements during this large-scale icing event are analysed, the comparative analysis of the disaster prediction and the actual situation of is carried out, and some suggestions are put forward for the prevention and control of power grid icing disaster in northern area.

\section{Analysis of meteorological conditions during the disaster}

Meteorological conditions are the immediate causes of transmission line icing and galloping [7-10]. This chapter mainly analyses the large-scale background circulation conditions and the evolution characteristics of key meteorological factors such as temperature, precipitation, wind speed and relative humidity when the disaster occurs in Jilin province.

\subsection{Background conditions of large scale circulation}

The strong WPSH is abnormally northward, which results in the warm and humid air from the south transported to the central of Northeast China, The high-altitude trough changed from horizontal trough to vertical trough, leading the strong cold air in the north to affect China from northwest area to northeast area. The confluence of cold and warm air in the central of Northeast China is the circulation back-ground condition for the formation of this icing and galloping disaster event.
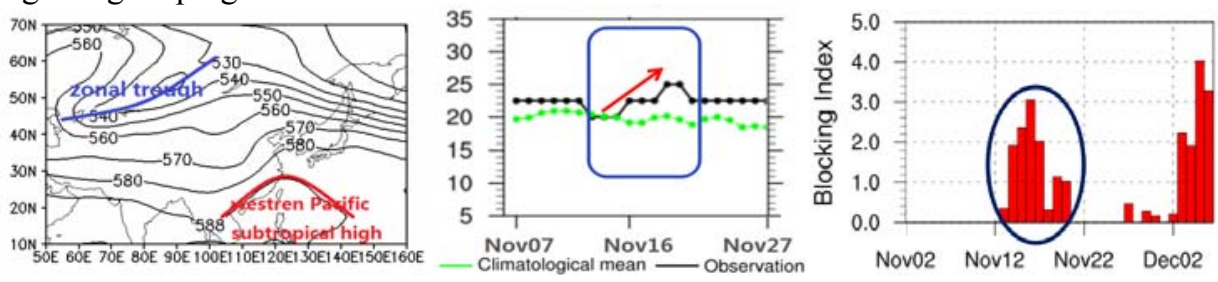

Fig. 1. Atmospheric circulation during this icing and galloping disaster (Left: atmospheric circulation pattern at $500 \mathrm{hPa}$ on November 17, 2020; Middle: the ridge position of the WPSH during this disaster; Right: the Urals blocking high system during this disaster).

It can be seen from figure 1(middle), before the occurrence of the icing and galloping disaster, the ridge line of the WPSH, which represents the north-south position of the WPSH, pushed northward to $26^{\circ} \mathrm{N}$, which was abnormally northward than the climatological mean $\left(19^{\circ} \mathrm{N}\right)$. The WPSH guides the water vapor from the south to the north, leading to more water vapor anomalies in the Northeast China. According to the measured data from the surface meteorological stations of China Meteorological Administration, a 
25-50 $\mathrm{mm}$ precipitation process occurred in the central and southern part of Northeast China, North China and the Yangtze Huaihe River Basin during November 18-22 (Fig 2).

It can be seen from figure 1(right), before the occurrence of the icing and galloping disaster, there was an obvious blocking high system occurred near the Ural Mountains. The development stage of blocking high system is beneficial to the accumulation of cold air, and the collapse stage of blocking high system is beneficial to the southward movement of cold air in the north, resulting in the cooling process in China. According to the measured data from the surface meteorological stations of China Meteorological Administration, there was a cooling process from northwest to northeast in China during November 18-22, and the average temperature in northern China was $2-4^{\circ} \mathrm{C}$ lower than that in the same period in history (Fig 2).
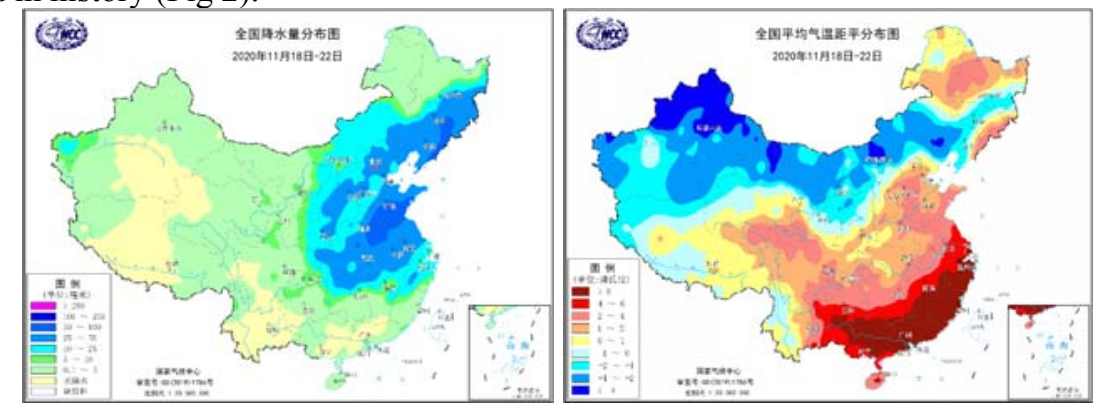

Fig. 2. Distribution characteristics of precipitation and temperature decline from November 18 to 22 (Left for precipitation, Right for temperature. Quoting from http://www.ncc-cma.net/cn/).

\subsection{Evolution characteristics of key meteorological elements}

Previous studies have shown that the meteorological conditions for galloping include: temperature below $0^{\circ} \mathrm{C}$, wind speed between $4-20 \mathrm{~m} / \mathrm{s}$, precipitation or humidity higher than $85 \%$ [11-13]. This chapter analyses the development process of the icing and galloping disaster based on the hourly temperature, precipitation, wind speed and relative humidity observation data of surface meteorological stations, which provide basis for the prediction and early warning of the galloping event in the future [14-19].

As shown in Figure 3, in Songyuan city of Jilin province, the temperature dropped to below $0^{\circ} \mathrm{C}$ after 00:00 on the 18th and kept decreasing; the precipitation started at 00:00 on the 19th and lasted until 01:00 on the 20th, with the accumulated precipitation of $23 \mathrm{~mm}$; the wind speed began to increase rapidly at $07: 00$ on the 18th and dropped to below $4 \mathrm{~m} / \mathrm{s}$ at 00:00 on the 20th; the humidity maintained above $85 \%$ from 00:00 on the 19 th to $00: 00$ on the 20th. Among them, between 00:00 on the 19th and 00:00 on the 20th, the weather conditions were below zero degrees Celsius, precipitation, strong wind and high humidity, which met the meteorological conditions for transmission line galloping.

In Changchun city of Jilin province, the temperature dropped to below $0^{\circ} \mathrm{C}$ after 11:00 on the 18th and kept decreasing; the precipitation started at 20:00 on the 17th and lasted until 04:00 on the 20th, with the accumulated precipitation of $34.3 \mathrm{~mm}$; the wind speed began to increase rapidly at $08: 00$ on the 18 th and dropped to below $4 \mathrm{~m} / \mathrm{s}$ at 22:00 on the 19th; the humidity maintained above $85 \%$ from $21: 00$ on the 17 th to $10: 00$ on the 20 th. Among them, from 11:00 on the 18 th to $22: 00$ on the 19 th, the weather conditions were below zero degrees Celsius, precipitation, strong wind and high humidity, which met the meteorological conditions for transmission line galloping.

In Jilin city of Jilin province, the temperature dropped below $0^{\circ} \mathrm{C}$ at $12: 00$ on the 18 th and kept decreasing; the precipitation started at 15:00 on the 18th and lasted until 09:00 on the $20 \mathrm{th}$, with the accumulated precipitation of $59 \mathrm{~mm}$; the wind speed began to increase at 
13:00 on the 18th and the strong wind lasted until 07:00 on the 20th; the humidity was above $85 \%$ from $00: 00$ on the 18th to $08: 00$ on the 21 st. Among them, from 15:00 on the 18th to 07:00 on the 20th, the weather conditions were below zero degrees Celsius, precipitation, strong wind and high humidity, which met the meteorological conditions for transmission line galloping.

In Siping City of Jilin province, the temperature dropped to below $0^{\circ} \mathrm{C}$ at $18: 00$ on the 18th and kept decreasing; the precipitation began on the 14th of the 18th and ended at 19:00 on the 19 th, with a cumulative precipitation of $27 \mathrm{~mm}$; the wind speed began to increase at 06:00 on the 18th and the strong wind continued until 5:00 on the 20th; the humidity maintained above $85 \%$ from $00: 00$ on the 18 th to $08: 00$ on the 20 th. Among them, from 18:00 on the 18 th to $19: 00$ on the 19 th, the weather conditions were below zero degrees Celsius, precipitation, strong wind and high humidity, which met the meteorological conditions for transmission line galloping.
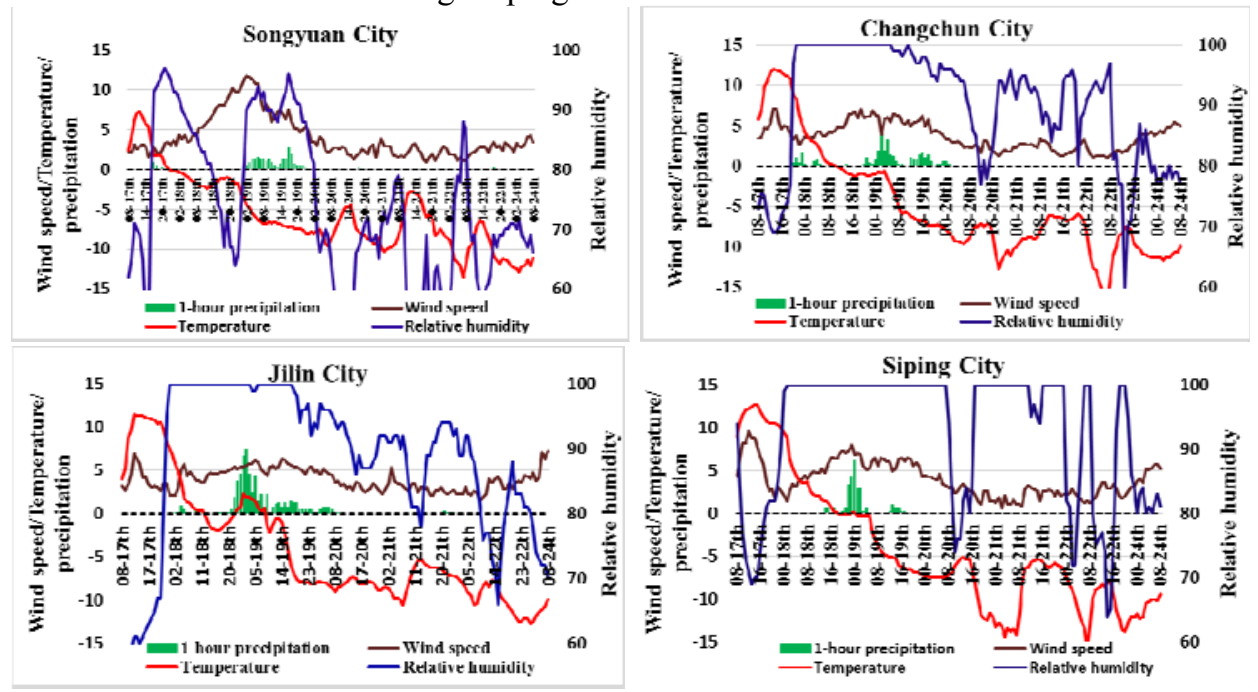

Fig. 3. Evolution characteristics of hourly temperature, precipitation, wind speed and relative humidity in Songyuan, Changchun, Jilin, and Siping. (Red line for temperature, unit: ${ }^{\circ} \mathrm{C}$; Brown line for wind speed, unit: $\mathrm{m} / \mathrm{s}$; Green bar for hourly precipitation, unit: $\mathrm{mm}$; Blue line for relative humidity, unit: \%)

\section{Comparative analysis of disaster prediction and actual situation}

This chapter mainly analyses the disaster prediction and actual situation of the large-scale icing and galloping event in Jilin Province.

\subsection{Actual situation of disaster}

From November 18 to 22, 2020, affected by the freezing disaster in Jilin province, the transmission line icing and galloping fault mainly occurred in Changchun, Jilin, Siping, and Songyuan city, and a total of 179 lines with voltage level of $66 \mathrm{kV}$ and above have faults due to icing and galloping (Fig. 4). 


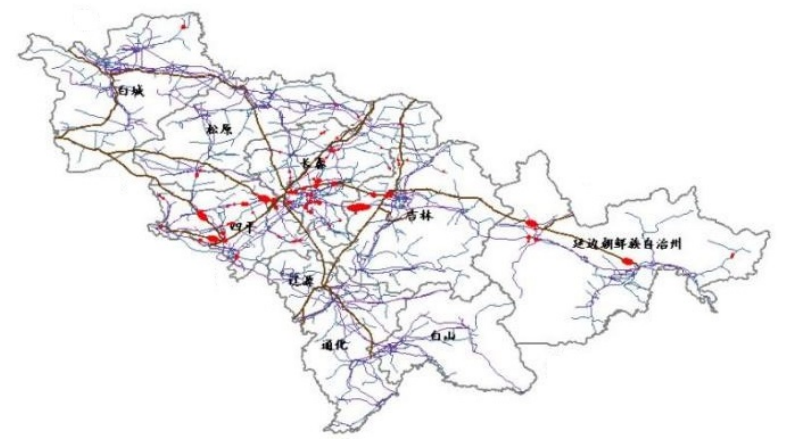

Fig. 4. Distribution of power grid fault points (red mark) during November 18-22, 2020.

From the analysis of fault time, the trans-mission line fault time is mainly concentrated from 14:00 on November 18 to $12: 00$ on November 19, accounting for $87.71 \%$, which is consistent with the analysis results of meteorological elements evolution during the disaster.

From the analysis of fault types, there are 152 galloping faults, 22 icing overload faults and 5 de-icing jumps.

\subsection{Disaster prediction}

The icing prediction and early warning center of State Grid Corporation of China (State Key Laboratory of Disaster Prevention and Reduction for Power Grid Transmission and Distribution Equipment) is an organization specialized in icing and galloping prediction. It has developed and operated a set of numerical prediction system for power grid icing and galloping, the system can well predict icing and galloping disasters of State Grid Corporation of China in the next seven days.

According to the forecast results of the numerical prediction system on the 15 th November, there was a strong icing and galloping process in Jilin province from 18 to 22, the ice was mainly concentrated in Jilin City, Changchun, Siping and Songyuan, with the maximum ice thickness of $20 \mathrm{~mm}$; the dancing area was located in Songyuan, Jilin, Siping and Changchun, with the dancing level of level 2, which was prone to galloping trip. It can be seen from figure 4-5 that the disaster prediction result is consistent with the actual disaster situation.

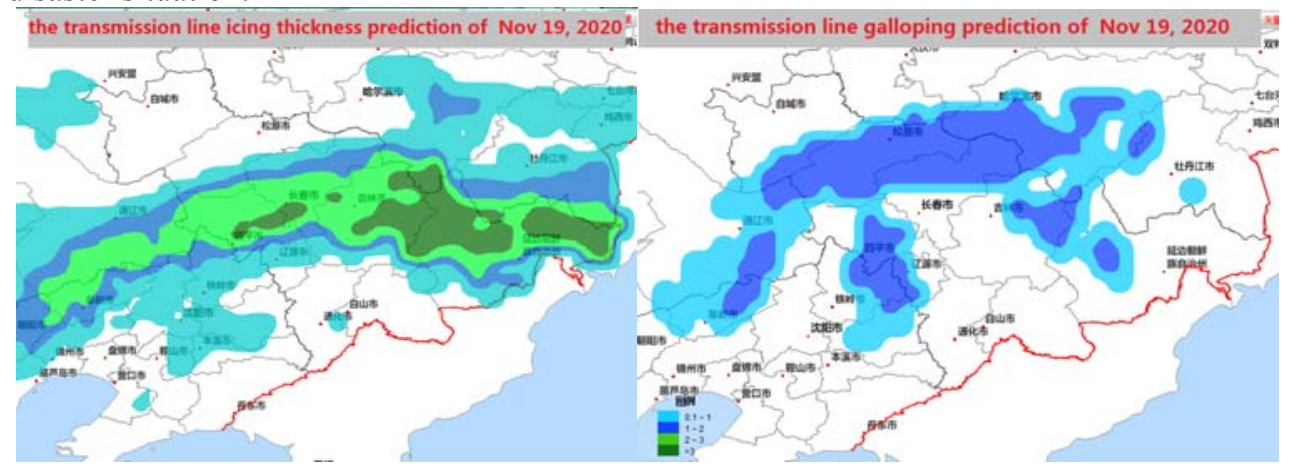

Fig. 5. Prediction of icing and galloping for this disaster (Left for icing, Right for galloping). 


\section{Discussion and suggestions}

(1) Pay more attention to the power grid icing and gal-loping disaster in northern China. With the climate change and the increase of extreme weather event, transmission line icing and galloping disasters in northern China occur frequently in recent 10 years. Six largescale icing and galloping events occurred in northern China, including January and February 2010 events, November 2012 event, November 2015 event, February and November 2020 event. Icing and galloping disasters in northern China have high frequency, wide area and great impact, so it is necessary to attach great importance to transmission lines in northern China.

(2) Actively carry out the prediction and early warning of icing and galloping disaster. In order to effectively reduce the disaster losses, we should carry out the research on the prediction and early warning technology of power grid icing and galloping disaster, release the warning in-formation in advance, support the power grid company to deploy deicing equipment, prepare emergency rescue materials, and make plans for load transfer of the galloping lines.

(3) Strengthen the equipment and emergency drills for dealing with freezing disasters in the power grid of Northern China. Compared with the southern region, the frequency of power grid freezing disaster in the northern region is less, the configuration of power grid ice disaster disposal equipment such as ice melting device is insufficient, and the personnel are lack of experience in dealing with freezing disaster.

\section{Acknowledgement}

This work was supported by the Science and Technology Project of State Grid Corporation of China (5216A019007J).

\section{References}

1. ZHU Kuanjun, YOU Yongchuan, ZHAO Yuanru. Electric Power Construction, 25(12), 18-21 (2004).

2. LIU Changsheng, LIU Hezhi, JIANG Dingyou, et al. Science Technology and Engineering, 14(24), 156-164 (2014).

3. YUAN Jihe, JIANG Xinliang, YI Hui, et al. High Voltage Engineering, 14(24), 156164 (2014).

4. ZHANG Lichun, ZHU Kuanjun. Power System and Clean Energy, 028(009), 1319,(2012).

5. WANG Shaohua, JIANG Xingliang, SUN Caixin. Transactions of China Electrotechnical Society, 25(001), 159-166 (2010).

6. FAN Shexin, HE Guojin, LIAO Xiaoping, et al. Proceedings of the CSEE. 14, 131-133 (2006).

7. WANG Jie, FAN Junhong, ZHAO Zengbao, et al. Journal of Arid Meteorology, 037(006), 1021-1027 (2019).

8. GAO Zhengxu, ZHOU Yuehua, XIAO Ying, et al. Journal of Catastrophology, 31(3), 73-77 (2016).

9. Zhao Bin, CHeng Yongfeng, Wang Jingchao, et al. Journal of Vibration and Shock, 36(10), 93-97 (2017). 
10. ZHANG Yongping, LIU Hongbin, DENG Chun, et al. Electric Power. 43(3), 27-30 (2010).

11. WANG Binlan, SONG Hongli, YUAN Chunhong, ZHOU Ning, ZHANG Xiaofei, YUAN Sikun. Meteorological Monthly, 043(001), 108-114 (2017).

12. XU Wangsheng, SUN Zhilin, GAO Bin, et al. High Voltage Engineering. 45(zk2) (2019).

13. YANG Fengli, YANG Jingbo, FU Dongjie, et al. Proceedings of the CSEE, 31(016), 102-107 (2011).

14. LIU Yakun, LI Linrui, LI Shilong, FU Zhengcai. Journal of Shanghai Jiao TongUniversity. 50, 825-830 (2016).

15. LI Xinmin, ZHU Kuanjun, LIU Bin. High Voltage Engineering, 40(2), 427-433 (2014).

16. Xiang Lin, Zhou Chenguang, and Tang Liang. Chinese Journal of Construction Machinery, 017(002),127-133 (2019).

17. HU Yi. High Voltage Engineering. 31(004), 14-15 (2005).

18. CHU Shuangwei, XIONG Xiaofu, LIU Shanfeng,et al. Power System Protection and Control, 507, 93-100, (2018).

19. Jin Shuanglong, Feng Shuanglei, Liu Xiaolin, et al. Atmospheric and Oceanic Science Letters, 100022, (2020). 